\title{
Tremor and other movement disorders after whiplash type injuries
}

\author{
Simon J Ellis
}

\begin{abstract}
Movement disorders are usually of central origin, but have been reported in association with peripheral trauma. Injuries to the neck of the whiplash type provide a source of both types of injuries. Six cases are reported in which the temporal relation between the injury and the movement disorder make a causal relation likely. This important cause of disability has not previously been appreciated.
\end{abstract}

(F Neurol Neurosurg Psychiatry 1997;63:110-112)

Keywords: whiplash injury; tremor; movement disorder

In my general and medicolegal practice I have been struck by the number of patients who have had whiplash type injuries to the cervical spine and who have subsequently developed movement disorders. My clinical experience is not mirrored in the literature and so I offer this series derived from my own practice over a two year period.

\section{Case histories}

CASE 1

A 56 year old retired cook was a passenger in a car which was stationary when it was hit from behind by a saloon car. She was wearing a seat belt and the car was fitted with head restraints. She remembered being thrown forwards then backwards and immediately had a pain in the neck. Immediately after the accident she developed a tremor in both hands. This continued to the time of examination, 15 months after the accident. Her neck remained stiff and painful. Seven months after the accident she developed a frozen left shoulder. Ten and eight years before the accident she had had short periods of neck pain associated with paraesthesiae in the arms. There is no family history of tremor or movement disorder.

On examination neck movements were limited by stiffness and pain. The trapezius was in spasm bilaterally. Passive left shoulder movements were limited by pain. The deep tendon reflexes and motor and sensory examination were normal. There was no cogwheeling or increased tone in the limbs. There was a pronounced bilateral tremor, worse on the right then the left. It was most prominent at the wrists and was of a flexionextension type, present at rest, but exacerbated by intention. ${ }^{1}$ The tremor involved the proximal arms up to the shoulders.

CASE 2

A 24 year old secretary was sitting in her stationary car when it was hit from behind. She was thrown forwards, restrained by her seat belt, and hit the back of her head against the head rest. Within an hour she had developed a pain in the neck radiating into both arms, associated with paraesthesiae in both arms, but predominantly in the right C5 and C6 distribution. Two weeks after the trauma she developed a tremor in her right hand, particularly on performing activities. She could no longer carry a full cup of coffee and had difficulty holding pen or paper. The neck pain settled to become only intermittent, but the tremor persists 12 months after the accident. Before the trauma she had a very mild tremor, of a different character, present in both hands when under stress.

Examination showed mild restriction of neck movements by pain and spasm in the trapeziae, worse on the right. Tone in the limbs was normal. There was slight weakness of hand grip and opponens pollicis on the right. Pin prick sensation was reduced in a C6 distribution in the hand. There was a $6-8 \mathrm{~Hz}$ action type tremor, particularly present when the right wrist was extended or flexed and also when the thumb was flexed.

Plain cervical spine radiography showed loss of the normal curvature and MRI of the cervical spine was normal.

CASE 3

A 42 year old right handed woman was involved in a road traffic accident which resulted in an injury to the occipital region and whiplash type flexion/extension injury to the neck. Six months after the trauma she noticed that she had developed a progressive tremor of her left arm associated with intermittent paraesthesiae in that arm. There was no family history of tremor or movement disorder.

Four years later on examination she had an intention tremor which was bilateral, but worse on the left. There was no past pointing or and in revised form 24

February 1997

Accepted 3 March 1997 
dysdiadochkinesia. Pin prick was decreased in the left C6 to C8 dermatomes. There was hypertonia in both upper limbs. Her left leg was mildly weak and there was decreased pin prick in an L2 to L5 distribution. She was slightly hyperreflexive in the upper limbs, the left ankle jerk was reduced, and the left plantar was extensor whereas the right was flexor.

Brain MRI was normal. Cervical spine MRI showed a discal protrusion at $\mathrm{C} 2-3$ and at C3-4, the second abutting the left C4 root. At C5-6 discal protrusion deformed the anterior surface of the cord as well as the right C6 root. Nerve conduction studies were normal; EMG showed minor irregularities in motor unit morphology in brachioradialis and abductor digiti minimi.

CASE 4

An 18 year old student was involved in a collision with another car; she was thrown forward and restrained from hitting her head by her seat belt. Two hours after the accident she developed neck pain radiating across the shoulders and down the back. The next day the pain became severe. Two weeks after the accident she became aware of tremulousness at the wrists. This was exacerbated by attempts to do fine movements such as threading a needle and by stress. The tremor worsened over the first year, then became less pronounced, but was still present two years after the accident. She had occasional paraesthesiae in the hands.

One year after the accident there was no restriction on neck movements nor any pain. Examination of the limbs was normal in power, tone, sensation (including proprioception), and coordination. When she held out her hands there were small, involuntary, irregular, adduction/abduction movements of both the fingers and flexion movements of the wrists which were exacerbated if the wrists were dorsiflexed.

CASE 5

A 25 year old chef was driving at around 30-35 $\mathrm{mph}$ when a car crossed in front of him causing a collision. He was thrown forwards, restrained by his seat belt, and thrown backwards into his seat, which was fitted with a head rest. Immediately after the accident he had some neck pain which resolved over about two weeks. He had frontal headaches which lasted for six weeks after the accident. One year previously he had had an accident at work where he had slipped on a wet floor, wrenched

Table 1 Summary of data for the six patients

\begin{tabular}{|c|c|c|c|c|}
\hline $\begin{array}{l}\text { Case } \\
\text { No }\end{array}$ & Age & Sex & $\begin{array}{l}\text { Time from } \\
\text { trauma to } \\
\text { tremor }\end{array}$ & $\begin{array}{l}\text { Type of tremor } 1 / \text { movement } \\
\text { disorder }\end{array}$ \\
\hline 1 & 56 & $\mathrm{~F}$ & Immediate & $\begin{array}{l}\text { Intention, flexion-extension } \\
\text { at the wrist }\end{array}$ \\
\hline 2 & 24 & $\mathrm{~F}$ & 2 weeks & $\begin{array}{l}\text { Action tremor of right wrists } \\
\text { and thumb }\end{array}$ \\
\hline 3 & 42 & $\mathrm{~F}$ & 6 months & Intention, bilateral \\
\hline 4 & 18 & $\mathrm{~F}$ & 2 weeks & $\begin{array}{l}\text { Adduction/abduction of the } \\
\text { fingers and at the wrist }\end{array}$ \\
\hline 5 & 25 & M & 6 months & Propriospinal myoclonus \\
\hline 6 & 18 & $\mathrm{~F}$ & 4 months & $\begin{array}{l}\text { Intention, } \\
\text { pronation/supination; task } \\
\text { specific focal dystonia }\end{array}$ \\
\hline
\end{tabular}

his neck, and developed severe low back pain. Subsequently this pain radiated into his left leg. Within six months of the road traffic accident he had developed a fidgety feeling in his left leg which had progressed into jerking movements of his trunk and lower limbs. Subsequently his upper limbs also became involved. There was no family history of movement disorders or tremor.

Examination disclosed no deficit in tone, power, sensation, or coordination in the limbs. The deep tendon reflexes were normal and the plantars were flexor. During the examination there were jerking episodes about every two minutes with flexion of the trunk, adduction and flexion of the legs, and abduction of the arms. Tendon taps to the knees and ankles would cause upper body jerks.

Cervical and thoracic spine MRI showed no gross abnormality but the images were degraded by motion artifact. Electrophysiological examination suggested an origin for his jerks in the low cervical/high thoracic cord on the basis of the delays between EMG activity in the right leg adductor, right rectus abdominus, left pectoralis, left biceps, and right sternomastoid.

His propriospinal myoclonus was resistant to treatment with valproate and clonazepam and has worsened over the two years since it developed.

CASE 6

An 18 year old filing clerk was involved in a head on road traffic accident in which she was thrown forwards hitting her head on the steering wheel, despite her seat belt. She was then thrown backwards and to her left and struck her head on her passenger's head. She lost consciousness for about 30 seconds. On arrival in hospital she developed neck pain that radiated into her right shoulder. The pain in the neck and shoulder gradually resolved over six months. Within two weeks of the accident she had developed migraine type headaches. Four months after the accident she noticed a tremor in her right hand when picking up a cup. This intention type tremor was exacerbated by stress. It was of a pronation/supination type and intermittent in nature. In addition she developed cramping in the right hand when undertaking repetitive fine motor activities such as typing. There was no family history of movement disorders. Her general mood was good, but she had detailed flashbacks of the accident. Her mother had committed suicide by means of a road traffic accident.

Examination 21 months after the accident showed full neck movements with some minor pain in the right shoulder on rotating the head to the right. There was hyperaesthesiae in her right hand to pin prick. Not only was the stimulus sharper than on the left, but it was more prolonged.

\section{Discussion}

All these cases had whiplash type neck injuries in road traffic accidents (table). The degree of disability from the whiplash injury varied from the trivial (case 3) to the severe (case 1). These patients developed a movement disorder 
between immediately and six months after the accident. In all cases the movement disorder has been persistent, although in case 4 the tremor began to ease after one year. There was evidence of root damage in cases 2,3 , and 6 and cord damage in case 3 and probably 5 . There was no family history of movement disorder in any of the cases.

It is unlikely that psychological factors played a major part in the genesis of their movement disorders. Only one case had any features of post-traumatic stress disorder and in her case (case 6) they were relatively mild. Although many were involved in litigation, not all were and other aspects of their injuries had settled, making secondary gain from litigation an unlikely cause for any psychological hypothesis. It has previously been shown that the symptoms from whiplash injury do not resolve on settling of compensation claims as would be expected if litigation was important in maintaining symptomatology. ${ }^{2}$

The relation between trauma and movement disorders has been controversial. ${ }^{3}$ Movement disorders are usually attributed to central mechanisms; $16.4 \%$ of patients with ideopathic torsion dystonia gave a history suggesting that their movement disorder had been precipitated by trauma. ${ }^{4}$ Just under half had affected relatives, but only one of the 17 cases described had a neck injury. In a series of 28 patients who had developed tremor or dystonia within 12 months of trauma there was evidence of both peripheral and central dysfunction. ${ }^{5}$

In my series case 6 showed some hyperpathia in the hand that developed the tremor and dystonia.Eighteen cases of dystonia in association with causalgia have been reported and named the "causalgia-dystonia syndrome". ${ }^{6}$ Although sensory disturbance in case 6 is less severe than those reported in that paper, she could fit into that rubric.

Ideopathic torsion dystonia and peripheral induced dystonia are reported to have a female preponderance. $^{7}$ In the current series five out of six of the patients were women. This may reflect the higher incidence of joint laxity in the female population ${ }^{8}$ with a greater degree of flexion-extension resulting from this type of injury.

The cases presented in this paper all comply with the criteria suggested by Jankovic ${ }^{7}$ that:

- Injury must have been severe enough to cause local symptoms for two weeks
- The onset of the movement disorder should be within a year of the injury

- The movement disorder must have an anatomical association with the site of the injury.

Although this sort of evidence is circumstantial and to my mind compelling, a more rigorous study may be unrealistic. Only a large study of patients with whiplash type injury and a matched control group would determine if there was an increased incidence of movement disorder and then the nature of that relation would still remain undefined. In addition, if movement disorders as a result of whiplash injury occurred in $5 \%$ of patients, but are present in $1 \%$ of the non-traumatised population then a study of about 400 subjects would be needed. If the incidence is any lower in the whiplash patients then the study size would be larger and becomes even more impractical.

Seventy five per cent of patients make a complete recovery from whiplash type injury within a year; however, more severe neck injury is associated with delayed recovery. ${ }^{9}$ It is surprising, given the frequency of whiplash type injury and the likelihood of damage to both roots and the cord that associated movement disorders have not been previously well recognised. The variable time between injury and onset during which most of these patients fail to come to neurological attention and the propensity to attribute symptoms that are difficult to explain to psychological mechanisms, may be important in the underappreciation of these disabling conditions.

1 Bain P. A combined clinical and neurophysiological approach to the study of patients with tremor. $f$ Neurol Neurosurg Psychiatry 1993;69:839-44.

2 Mendelson G. Not "cured by a verdict". Effect of legal settlement on compensation claimants. Med F Aust 1982;ii: $132-4$.

3 Koller WC, Wong GF, Lang A. Posttraumatic movement disorders: a review. Mov Disord 1989;4:20-36.

4 Fletcher NA, Harding AE, Marsden CD. The relationship between trauma and idiopathic torsion dystonia. 7 Neurol between trauma and idiopathic tors

5 Jankovic J, Vab der Linden C. Dystonia and tremor induced by peripheral trauma: predisposing factors. $\mathcal{F}$ Neurol Neurosurg Psychiatry 1988;51:1512-9.

6 Bahatia KP, Bhatt MH, Marsden CD. The causalgiadystonia syndrome. Brain 1993;116:843-51.

7 Jankovic J. Post-traumatic movement disorders: central and peripheral mechanisms. Neurology 1994;44:2006-14.

8 Larsson L-G, Baum J, Muholkar GS. Hypermobility: features and differential incidence between the sexes. Arthritis Rheum 1987;30:1426-30.

9 Radanov BP, Sturzenegger M, Distefano M, Schnidrig A, Munmenthaler M. Results of one-year follow-up-study after whiplash injury. Schweiz Med Wochenschr 1993;123: 1545-52. 